\title{
The Pathobiology of H7N3 Low and High Pathogenicity Avian Influenza Viruses from the United States Outbreak in 2020 Differs between Turkeys and Chickens
}

\author{
Miriã F. Criado ${ }^{1,+, \ddagger}$, Christina M. Leyson ${ }^{1,+}+{ }^{+}$, Sungsu Youk $^{1}{ }^{1}$, Suzanne DeBlois ${ }^{1}$, Tim Olivier ${ }^{1}$, \\ Mary Lea Killian ${ }^{2}$, Mia L. Torchetti ${ }^{2}$, Darren J. Parris ${ }^{1}$, Erica Spackman ${ }^{1}$, Darrell R. Kapczynski ${ }^{1}$, \\ David L. Suarez ${ }^{1}$, David E. Swayne ${ }^{1}$ and Mary J. Pantin-Jackwood ${ }^{1, *}$
}

1 Exotic and Emerging Avian Viral Diseases Research Unit, Southeast Poultry Research Laboratory, U.S. National Poultry Research Center, Agricultural Research Service, U.S. Department of Agriculture, Athens, GA 30605, USA; mcriado@uga.edu (M.F.C.); christina.leyson@usda.gov (C.M.L.); sungsu.youk@usda.gov (S.Y.); suzanne.deblois@usda.gov (S.D.); tim.olivier@usda.gov (T.O.); dparri11@gmail.com (D.J.P.); erica.spackman@usda.gov (E.S.); darrell.kapczynski@usda.gov (D.R.K.); david.suarez@usda.gov (D.L.S.); david.swayne@usda.gov (D.E.S.)

2 National Veterinary Services Laboratories, Animal and Plant Health Inspection Service, U.S. Department of Agriculture, Ames, IA 50010, USA; mary.1.killian@usda.gov (M.L.K.); mia.kim.torchetti@usda.gov (M.L.T.)

check for updates

Citation: Criado, M.F.; Leyson, C.M.; Youk, S.; DeBlois, S.; Olivier, T.; Killian, M.L.; Torchetti, M.L.; Parris, D.J; Spackman, E.; Kapczynski, D.R.; et al. The Pathobiology of H7N3 Low and High Pathogenicity Avian Influenza Viruses from the United States Outbreak in 2020 Differs between Turkeys and Chickens. Viruses 2021, 13, 1851. https://doi.org/10.3390/ v13091851

Academic Editor: Mathilde Richard

Received: 19 August 2021

Accepted: 11 September 2021

Published: 16 September 2021

Publisher's Note: MDPI stays neutral with regard to jurisdictional claims in published maps and institutional affiliations.

Copyright: () 2021 by the authors. Licensee MDPI, Basel, Switzerland. This article is an open access article distributed under the terms and conditions of the Creative Commons Attribution (CC BY) license (https:// creativecommons.org/licenses/by/ $4.0 /)$.
* Correspondence: mary.pantin-jackwood@usda.gov; Tel.: +1-706-5463419

+ Authors contributed equally to this study.

$\ddagger$ Current address: Center for Vaccines and Immunology, College of Veterinary Medicine, University of Georgia, Athens, GA 30602, USA.

Abstract: An outbreak caused by H7N3 low pathogenicity avian influenza virus (LPAIV) occurred in commercial turkey farms in the states of North Carolina (NC) and South Carolina (SC), United States in March of 2020. Subsequently, H7N3 high pathogenicity avian influenza virus (HPAIV) was detected on a turkey farm in SC. The infectivity, transmissibility, and pathogenicity of the H7N3 HPAIV and two LPAIV isolates, including one with a deletion in the neuraminidase (NA) protein stalk, were studied in turkeys and chickens. High infectivity $\left[<2 \log _{10} 50 \%\right.$ bird infectious dose $\left(\mathrm{BID}_{50}\right)$ ] and transmission to birds exposed by direct contact were observed with the HPAIV in turkeys. In contrast, the HPAIV dose to infect chickens was higher than for turkeys $\left(3.7 \log _{10}\right.$ $\left.\mathrm{BID}_{50}\right)$, and no transmission was observed. Similarly, higher infectivity $\left(<2-2.5 \log _{10} \mathrm{BID}_{50}\right)$ and transmissibility were observed with the H7N3 LPAIVs in turkeys compared to chickens, which required higher virus doses to become infected (5.4-5.7 $\log _{10} \mathrm{BID}_{50}$ ). The LPAIV with the NA stalk deletion was more infectious in turkeys but did not have enhanced infectivity in chickens. These results show clear differences in the pathobiology of AIVs in turkeys and chickens and corroborate the high susceptibility of turkeys to both LPAIV and HPAIV infections.

Keywords: H7N3; high pathogenicity avian influenza; low pathogenicity avian influenza viruses; chickens; turkeys; infectivity; pathogenicity; transmission

\section{Introduction}

Avian influenza viruses (AIV) are type A influenza viruses belonging to the Orthomyxoviridae family and are classified into subtypes based on the two viral surface glycoproteins: the hemagglutinin (HA) and the neuraminidase (NA). The virus is further classified as either low pathogenicity (LP) or high pathogenicity (HP) based on lethality in chickens or sequence determination of the HA cleavage site of $\mathrm{H} 5$ and $\mathrm{H} 7$ subtypes that is consistent with HP viruses [1,2]. Wild aquatic birds are the natural reservoir of AIVs; viruses from these species are usually of the LP phenotype, and infections are asymptomatic [2]. Periodically, these LPAIVs transmit from wild to domestic birds, resulting in subclinical infections, mild respiratory disease, and/or drops in egg production [3]. After circulating 
in chickens or turkeys, $\mathrm{H} 5$ and H7 LPAIVs have mutated on numerous occasions to HPAIV, causing poultry outbreaks worldwide [2,4].

Between 1955 and 2019, forty-two unique lineages of HPAIV outbreaks have been reported around the world [4]. In the Americas in the last 20 years, H7 HPAIV outbreaks in poultry have occurred in Chile (H7N3) in 2002 [5], in Canada (H7N3) in 2004 [6] and 2007 [7], and in Mexico in 2012 (H7N3), with the latter virus becoming endemic in this country [8-10]. In the United States (US) in 2016, H7N8 HPAIV and its LPAIV precursor were detected in a turkey flock in Indiana [11]. In 2017, H7N9 HPAIV was identified in two broiler breeder farms in Tennessee, with the precursor LPAIV found in multiple broiler breeder farms and backyard poultry in Tennessee and neighboring states [12].

In March 2020, an outbreak of H7N3 LPAIV occurred in turkey farms in North Carolina and South Carolina [13]. In April 2020, an H7N3 HPAIV was also detected in one of the turkey premises. Around 400,000 birds were depopulated to control the outbreak [13]. Whole genome sequencing of the viruses from this outbreak showed that the H7N3 gene segments have a North American wild bird origin and are genetically distinct from the viruses previously identified in the 2016 and 2017 US H7N8 and H7N9 outbreaks, respectively [13]. Although they are the same HA and NA subtype, the 2020 H7N3 viruses are genetically distinct from the Mexican H7N3 HPAIVs that have been circulating in poultry since 2012. The 2020 US H7N3 virus isolates were all highly similar to each other, indicating a single introduction of a wild bird H7N3 LPAIV into turkeys with subsequent mutation to HPAIV [13]. Two notable genetic changes were identified among the virus isolates: a multibasic cleavage site in the HA gene present in the HPAIV isolates and a deletion in the NA stalk region found in some of the LPAIV isolates from the outbreak [13]. Deletions in the NA stalk have been previously associated with adaptation to gallinaceous species [14-17].

In an effort to improve the control of LPAIV and HPAIV in poultry and increase understanding of the pathobiology of these viruses in gallinaceous species, in this study, we characterized the infectivity, transmissibility, and pathogenicity of two H7N3 LPAIVs, one of them with the NA stalk deletion and one of the HPAIV isolates from the 2020 outbreak in the two most important poultry species, turkeys and chickens.

\section{Materials and Methods}

\subsection{Viruses}

Two LPAIV isolates, A/turkey/South Carolina/20-008394-1/2020 (H7N3) (LPAIV-1) (GenBank accession number MT444368-MT444375) and A/turkey/North Carolina/20008425-1/2020 (H7N3) (LPAIV-2) (GenBank accession number MT444287-MT444294), and one HPAIV, A/turkey/South Carolina/20-010561-006/2020 (H7N3) (HPAIV) (GenBank accession number MT444408-MT444415), were used in this study. The viruses were isolated from an active surveillance testing program in North Carolina and South Carolina, US, during March-April 2020, and sequenced [13]. The virus isolates were kindly provided by the National Veterinary Services Laboratories (NVSL) of the US Department of Agriculture, Animal and Plant Health Inspection Service (USDA-APHIS). The working virus stocks were propagated and titrated by allantoic sac inoculation of 9- to 10-day-old embryonated chicken eggs (ECE) by standard methods [18]. The LPAIVs differed mainly by a 66 nucleotide (nt) deletion in the NA stalk region of LPAIV-2. The HPAIV had a $27 \mathrm{nt}$ insertion in the HA cleavage site compared to the LPAIVs and did not have the NA stalk deletion [13]. Next-generation sequencing conducted in our laboratory [19] determined that the HPAIV isolate was a mix of LPAIV and HPAIV. To obtain a preparation with only HPAIV, the first ECE passage of the field HPAIV isolate was passaged in 10-day-old ECEs and then passaged a second time in 14-day-old ECEs, which is a procedure that has been shown to select for HPAIV [20,21]. Brain tissue harvested from embryos after the second ECE passage were homogenized and subjected to another passage in 14-day-old ECEs. This last passage in ECE was used as inoculum. Sequence reads from randomly amplified RNA in the last ECE passage were assembled to the sequence of the original HPAIV isolate from the outbreak 
using BWA-MEM [22,23], and subsequently, variants were determined using Lofreq [24]. No variants lacking the multibasic cleavage site (MBCS) were detected, demonstrating that only viruses with the MBCS were in the HPAIV preparation. Brain-heart infusion (BHI) broth (Becton Dickinson and Company, Sparks, MD, USA) was used to dilute the virus stocks to the appropriate dose. Full genome sequencing was conducted of the inoculum used for all the three viruses and sequences compared to that of the original published (GenBank) field viruses. No changes were found in LPAIV-1 and LPAIV-2. The HPAIV used as inoculum had four amino acid changes when compared to the published GenBank sequence (D44N in matrix (M), T251S in neuraminidase (NA), D680N and L648M in polymerase basic protein (PB2) segments). Experiments were performed in a biosafety level-3 enhanced (BSL-3E) facility in accordance with procedures approved by the U.S. National Poultry Research Center (USNPRC) Institutional Biosecurity Committee, Agricultural Research Service (ARS), USDA.

\subsection{Animals and Housing}

One-day-old turkeys (Meleagris gallopavo) were provided by a commercial producer and reared at the USNPRC until three weeks of age. Four-week-old specific-pathogen free (SPF) White leghorn chickens (Gallus gallus) were obtained from the USNPRC in-house flocks. Birds were transferred to the animal biosafety level 3 enhanced (ABSL3E) facilities at the USNPRC, where each experimental group was housed in self-contained isolation units ventilated under negative pressure and inlet and outlet HEPA filtration. Turkeys and chickens had ad libitum access to food and water throughout the experiment. Housing and experimental procedures were reviewed and approved by the USNPRC Institutional Animal Care and Use Committee (IACUC).

\subsection{Experimental Design}

A total of 91 chickens and 61 turkeys were used in this study. The experimental design was similar to previous studies [25-27]. A reduced number of turkeys was used compared to chickens because of bird availability and the number of birds that could be housed per isolator. Ten birds of each species were bled prior to virus inoculation to confirm the absence of AIV antibodies by ELISA using the IDEXX AI MultiS-Screen ELISA kit (Westbrook, ME, USA) according to the manufacturer's protocol. Birds were divided into groups, and each group was inoculated intrachoanally with one virus at the appropriate dose to determine the $50 \%$ bird infectious dose $\left(\mathrm{BID}_{50}\right)$ for each virus in each bird species. The virus doses were initially intended to be 2 (low dose), 4 (medium dose), or 6 (high dose) $\log _{10} 50 \%$ egg infective dose $\left(\mathrm{EID}_{50}\right)$ in $0.1 \mathrm{~mL}$ per bird as in previous studies, but back titers of the LPAIVs inocula confirmed that the low dose was $2 \log _{10}$, the medium dose was $3 \log _{10}$, and the high dose was $5 \log _{10}$ EID $_{50}$. A separate identical experiment was repeated for the LPAIVs only in chickens using the dose of $6 \log _{10}$ EID $_{50}$ to obtain an endpoint to determine the $\mathrm{BID}_{50}$ for these viruses.

In all experiments, a group of sham-inoculated birds were inoculated intrachoanally with $0.1 \mathrm{~mL}$ of sterile allantoic fluid diluted 1:300 in BHI medium. In addition, to evaluate the transmissibility of each virus, two or three naïve birds from the same species were added to each dose group $24 \mathrm{~h}$ after inoculation (contact-exposed birds).

Oropharyngeal (OP) and cloacal (CL) swabs were collected at 12, 24 and $36 \mathrm{~h}$ postinoculation, followed by 2, 3, 4, 7, 10 and 14 days post-inoculation (dpi). All swabs were placed in brain-heart infusion (BHI) medium with penicillin (2000 units $/ \mathrm{mL}$; Sigma Aldrich, St. Louis, MO, USA), gentamicin $(200 \mu \mathrm{g} / \mathrm{mL}$, Sigma Aldrich; St. Louis, MO, USA) and amphotericin B (5 $\mu \mathrm{g} / \mathrm{mL}$, Sigma Aldrich; St. Louis, MO, USA) and stored at $-80{ }^{\circ} \mathrm{C}$ to determine virus shed titers. Two turkeys from the groups that received the high dose of HPAIV ( $\left.6 \log _{10} \mathrm{EID}_{50}\right)$ and three chickens from each of the three high-dose groups for each virus were euthanized and necropsied at 2 dpi. Brain, heart, spleen, lung, and muscle tissues were collected from these birds and stored at $-80^{\circ} \mathrm{C}$ for virus detection and quantification. All birds were observed daily for clinical signs and mortality from 0 to 
$14 \mathrm{dpi}$ (direct inoculates) or 0 to 13 days post-contact (dpc). Birds showing severe clinical signs including severe listlessness, neurological signs, respiratory distress, or inability to eat or drink were euthanized and counted as dead the next day for mean death time (MDT) calculations. At day 14, surviving birds were bled and euthanized.

Sera collected from all surviving birds was used to evaluate infection status by antibody levels using the hemagglutination inhibition (HI) assay. HI assays were performed using standard methods and homologous antigen [28]. Seroconversion was also confirmed by the ELISA test using the IDEXX AI MultiS-Screen ELISA kit (Westbrook, ME, USA). $\mathrm{HI}$ titers less than $3 \log _{2}$ GMT were considered negative. A signal-to-negative ratio (S/N) of greater than or equal to 0.5 was considered negative for the ELISA tests. HI assay and ELISA results were consistent with each other. The mean bird infectious dose $\left(\mathrm{BID}_{50}\right)$ for each virus was calculated by the Reed-Muench method [29], using the criteria that birds were considered infected if they shed detectable levels of virus at any time and/or were positive for antibody at the end of the study.

\subsection{Viral Titration in Swabs and Tissues}

Swab and tissue samples were processed for quantitative real-time RT-PCR (qRTPCR) to determine viral titers. We used a standard protocol that demonstrated the high correlation between qRT-PCR and the infectious titer determined in ECE as previously described [30]. Briefly, for oropharyngeal and cloacal swab samples, total RNA was extracted using MagMAX ${ }^{\mathrm{TM}}$-96 AI/ND Viral RNA Isolation $\mathrm{Kit}^{\circledR}{ }^{\circledR}$ (Ambion Inc./Thermo Fisher Scientific; Grand Island, NY, USA) according to the manufacturer's protocol. For tissues, samples were homogenized and resuspended in BHI media to a $10 \%(w / v)$ solution, and the total RNA was extracted from the homogenates using Trizol LS reagent (Invitrogen/Thermo Fisher Scientific; Grand Island, NY, USA) and chloroform (Life Technologies/Thermo Fisher Scientific, Carlsbad, CA, USA) according to the manufacturer's protocol. The resulting aqueous supernatants from tissue RNA extracts were purified using an RNA Clean and Concentrator kit (Zymo, Irvine, CA, USA), quantified by NanoDrop ${ }^{\mathrm{TM}}$ 1000 Spectrophotometer (Thermo Fisher Scientific) following the manufacturer's instructions, and diluted with Tris-EDTA buffer (10 mM Tris, $0.1 \mathrm{mM}$ EDTA, pH 7.5) to obtain $50 \mathrm{ng} / \mu \mathrm{L}$.

qRT-PCR was performed with the AgPath-ID One-Step RT-PCR kit (Ambion/Thermo Scientific; Grand Island, NY, USA) using a 7500 FAST real-time PCR system (Applied Biosystems, Foster City, CA, USA) and matrix-specific primers and a probe as previously described [27]. The standard curves for viral RNA quantification were established with 10fold dilutions of RNAs extracted from the same titrated stocks used for inoculation. Results were reported as $\mathrm{EID}_{50} / \mathrm{mL}$ or $\mathrm{EID}_{50} / \mathrm{g}$ equivalents, and the lower limit of detection was set based on each standard curve. The lower limit of detection was $1.8 \log _{10} \mathrm{EID}_{50} / \mathrm{mL}$ for LPAIV-1, $1.5 \log _{10}$ EID $_{50} / \mathrm{mL}$ for LPAIV-2, and $1.5 \log _{10} \mathrm{EID}_{50} / \mathrm{mL}$ for HPAIV. For statistical purposes, qRT-PCR negative samples were given a value of $0.1 \log _{10} \mathrm{EID}_{50} / \mathrm{mL}$ below the test limit of detection.

\subsection{Statistical Analysis}

Statistical analyses were performed using Prism 8 (GraphPad Software, San Diego, CA, USA; version 8.4.3). Virus RNA titers between OP and CL swabs were statistically compared at each time point using two-way ANOVA with Sidak's multiple comparisons. Statistical differences in the area under the curve of the plot between viral RNA titers, and time points were analyzed using one-way ANOVA with Sidak's multiple comparisons test. Those $p$ values $<0.05$ were considered significant.

\subsection{Sequence Analyses}

Phylogenetic trees were adapted using the same set of sequences from a previous study [13]. Whole genome sequences (GenBank numbers MT444183-350 and MT444352415) were obtained from the nucleotide database of the National Center for Biotechnology 
Information (NCBI). For each isolate, eight segments were concatenated in order of decreasing segment length. Concatenated sequences were aligned using MAFFT [31], and maximum likelihood trees were generated using RaxML as implemented in Geneious Prime 2019.2.3 (Biomatters Ltd.; Auckland, New Zealand) and the CIPRES Science Gateway [32]. Pairwise sequence identities among the concatenated genomes of the three virus isolates were calculated in Geneious Prime 2019.2.3. Additionally, pairwise differences among the genomes of the three isolates were identified and annotated using custom scripts in Python 3.8.5 (Conda version 4.10.1, https: / / anaconda.com; accessed on 3 September 2020). A sequence difference was considered nonsynonymous if the change results in an amino acid change in at least one protein encoded in the corresponding segment.

\section{Results}

\subsection{Infectivity, Transmission, and Pathogenicity of the H7N3 LPAIVs in Turkeys and Chickens}

Birds were considered infected if they shed virus and/or seroconverted by the end of the study ( $14 \mathrm{dpi}$ or $13 \mathrm{dpc}$ ). Results are presented in Table 1 . None of the turkeys inoculated with the low dose $\left(2 \log _{10}\right.$ EID $\left._{50}\right)$ of LPAIV-1 became infected; however, all turkeys were infected in the medium $\left(3 \log _{10} \mathrm{EID}_{50}\right)$ and high dose $\left(5 \log _{10} \mathrm{EID}_{50}\right)$ groups, resulting in a $\mathrm{BID}_{50}$ of $2.5 \log _{10} \mathrm{EID}_{50}$ (Table 1). Contact turkeys in the medium and highdose groups of LPAIV-1 were also infected. All turkeys in the LPAIV-2 groups, including contacts, were infected, resulting in a $\mathrm{BID}_{50}$ of $<2 \log _{10} \mathrm{EID}_{50}$ (Table 1).

All chickens inoculated with the highest dose $\left(6 \log _{10}\right.$ EID $\left._{50}\right)$ of LPAIV-1 and LPAIV-2 were infected. Only one chicken inoculated with $5 \log _{10}$ EID $_{50}$ of LPAIV-1, and one chicken from the groups inoculated with 3 or $5 \log _{10}$ EID $_{50}$ of LPAIV-2, respectively, were also infected (Table 1). The BID $_{50}$ was $5.7 \log _{10}$ EID $_{50}$ for LPAIV-1 and $5.4 \log _{10}$ EID $_{50}$ for LPAIV-2. Only one contact-exposed chicken in each of the LPAIV-1 and LPAIV-2 highest dose $\left(6 \log _{10}\right.$ EID $\left._{50}\right)$ groups was infected (Table 1$)$.

No or mild clinical signs (mild infraorbital swelling) were observed in the turkeys infected with either LPAIV or the contacts in these groups. However, one turkey inoculated with $3 \log _{10}$ EID $_{50}$ of LPAIV-2 and a contact from the same group were found dead at $11 \mathrm{dpi}$ and $3 \mathrm{dpc}$, respectively. Since these turkeys, or any other turkeys in this group, showed no clinical signs, and LPAIV was confirmed by sequencing the swab samples from these birds (no HPAIV), we concluded that the cause of death was not related to the LPAIV infection, since LPAIVs do not cause mortality if not complicated with other factors. No gross lesions were identified in the dead turkeys, and the cause of death was not determined. No clinical signs were observed in the chickens infected with the LPAIVs, and no gross lesions were observed in the birds necropsied at $2 \mathrm{dpi}$.

\subsection{Infectivity, Transmission, and Pathogenicity of the H7N3 HPAIV in Turkeys and Chickens}

All turkeys inoculated with the HPAIV at all three challenge doses, and the contacts in those groups, were infected and died, with mean death times (MDTs) between 2 and 2.4 days for inoculated turkeys and 3 days post-exposure for contacts (Table 1). The $\mathrm{BID}_{50}$ for this virus in inoculated turkeys was $<2 \log _{10} \mathrm{EID}_{50}$. The turkeys showed neurological signs (tremors, ataxia), lethargy, green diarrhea, mild periorbital swelling, and conjunctivitis. One turkey had blood in wing feather shafts. The gross lesions observed in the two turkeys necropsied at 2 dpi included congested internal organs, enlarged heart, and moderate splenomegaly with parenchymal mottling.

All chickens inoculated with the medium and high doses $\left(4\right.$ and $\left.6 \log _{10} \operatorname{EID}_{50}\right)$ of H7N3 HPAIV were infected, but only one chicken from the low dose $\left(2 \log _{10} \mathrm{EID}_{50}\right)$ group was infected. Thus, the BID 50 for H7N3 HPAIV in chickens was $3.7 \log _{10}$ EID $_{50}$. None of the contact chickens in this group were infected (Table 1). All infected chickens died, with MDTs between 1 and 1.6 days, which was about half a day shorter than for turkeys. In contrast to turkeys, which showed some clinical signs before death or euthanasia, most chickens died without showing clinical signs (peracute disease). Ruffled feathers, lethargy, anorexia, prostration, mild periorbital swelling, green diarrhea, and cyanotic combs were 
observed in the rest. The gross lesions observed in the necropsied chickens included congested internal organs and petechial hemorrhage in cecal tonsils.

\subsection{Viral Shedding and Virus Detection in Tissues}

Oropharyngeal (OP) and cloacal (CL) virus shedding was evaluated in inoculated and contact-exposed turkeys and chickens by qRT-PCR (Table 1). Figures 1 and 2 show the shedding results for the groups inoculated with the highest dose of the viruses. No viral RNA was detected in OP or CL swabs from turkeys inoculated with $2 \log _{10}$ EID $_{50}$ of LPAIV-1. However, all turkeys that received higher doses of LPAIV-1 ( 3 and $5 \log _{10}$ EID $_{50}$ ) shed virus, predominantly by the OP route, with some turkeys shedding virus by both routes after $7 \mathrm{dpi}$. All turkeys inoculated with LPAIV-2, independent of the inoculation dose, shed virus by the OP and CL route, with higher titers shed by the OP route at 3 and $4 \mathrm{dpi}$. Interestingly, at $14 \mathrm{dpi}$, the turkeys were shedding significantly higher titers by the $\mathrm{CL}$ route compared to the OP route $(p<0.05)$ (Figure 1$)$. The peak of OP virus shedding for both LPAIVs was between 3 and 7 dpi.

LPAIV-1
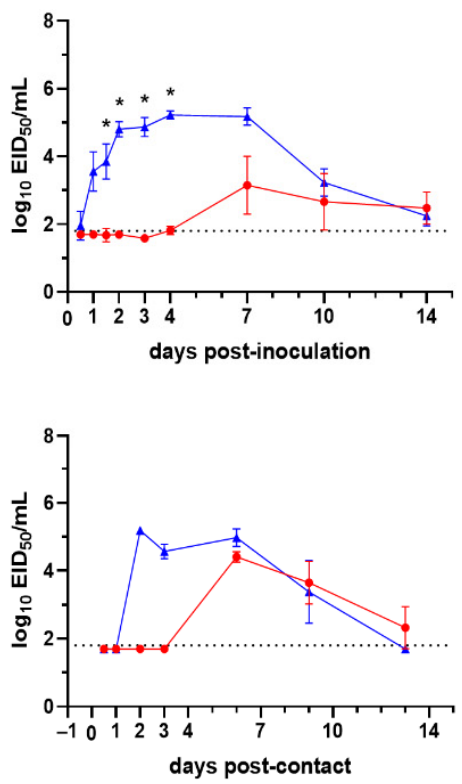

\section{LPAIV-2}
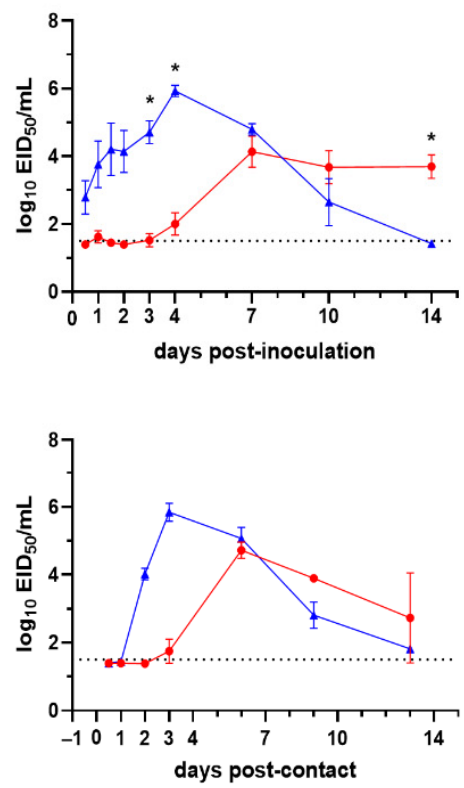

- Oropharyngeal swabs

- Cloacal swabs

HPAIV
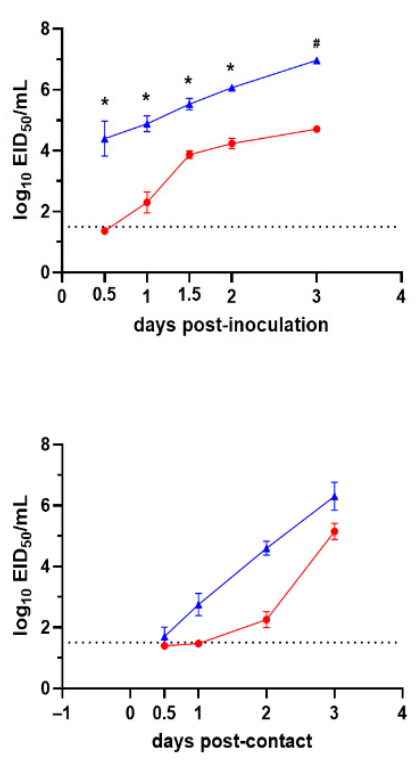

Figure 1. Virus shedding for turkeys inoculated with $5 \log _{10}$ EID $_{50}$ of LPAIV-1 and LPAIV-2 or $6 \log _{10}$ EID 50 of HPAIV and their respective contact-exposed turkeys. Virus titers from oropharyngeal (OP) (blue) and cloacal (CL) (red) swabs were determined by qRT-PCR. Dotted lines indicate the limit of detection for each virus. Asterisks $\left(^{*}\right)$ indicate statistically significant difference between OP and CL virus titers (one-way ANOVA with Sidak's multiple comparisons test; $p<0.05$ ). Only two contact birds were available; thus, no statistical test was performed for these groups. 
LPAIV-1
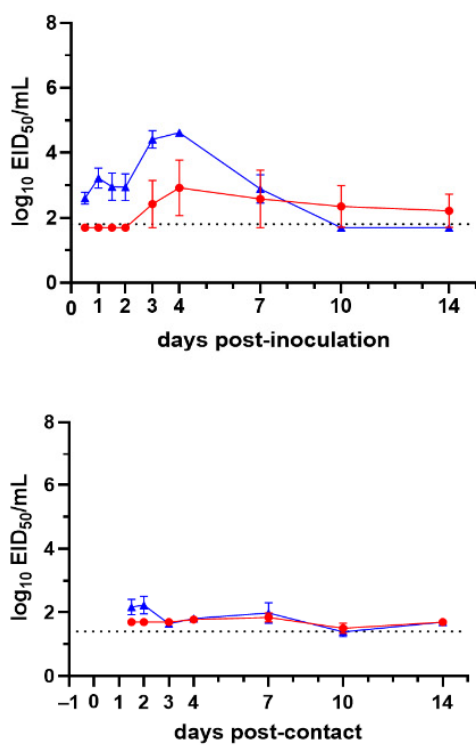

LPAIV-2
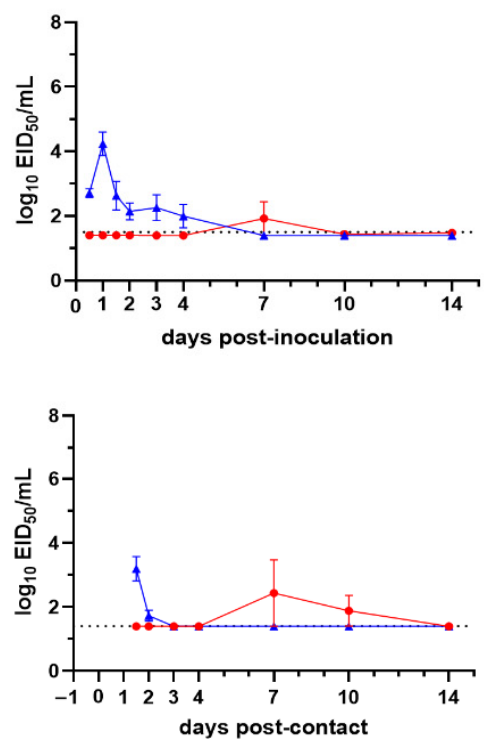

$\leftarrow$ Oropharyngeal swabs

$\rightarrow$ Cloacal swabs
HPAIV
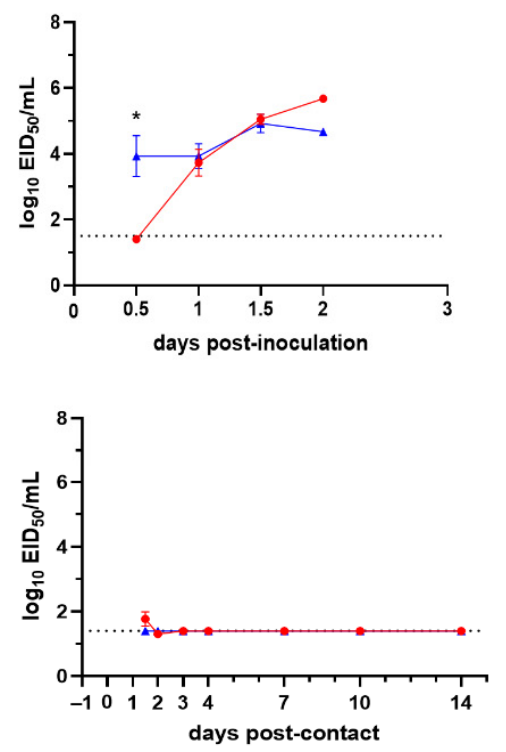

Figure 2. Virus shedding for chickens inoculated with $6 \log _{10}$ EID $_{50}$ of LPAIV-1, LPAIV-2, or HPAIV. Virus titers from oropharyngeal (OP) (blue) and cloacal (CL) (red) swabs were determined by qRT-PCR. Dotted lines indicate the limit of detection for each virus. Asterisks $\left(^{*}\right)$ indicate statistically significant difference between OP and CL virus titers (one-way ANOVA with Sidak's multiple comparisons test; $p<0.05$ ).

High viral titers were shed by all HPAIV-inoculated turkeys regardless of the dose received. Virus was detected at $12 \mathrm{~h}$ post-inoculation (hpi) from turkeys inoculated with $6 \log _{10} \mathrm{EID}_{50}$ (Figure 1). All turkeys shed HPAIV by the CL route, but virus titers were significantly lower than what were observed in OP swabs (Figure 1).

Independent of the virus and dose used, contact-exposed turkeys had similar shedding patterns to those observed in the inoculated turkeys (Figure 1), with virus detected in the OP samples at $2 \mathrm{dpc}$ and subsequently in both OP and CL samples in the following days (Figure 1).

In the chickens inoculated with the LPAIV-1 and LPAIV-2, OP virus shedding was detected in all the birds that received the highest virus dose $\left(6 \log _{10} \mathrm{EID}_{50}\right)$; but low or no virus was detected in CL samples (Figure 2 and Table 1). One chicken in the group inoculated with $5 \log _{10}$ EID $_{50}$ of LPAIV-1 and one chicken in each group that received 3 or $5 \log _{10}$ EID $_{50}$ of LPAIV-2 also shed virus (Table 1). The chickens inoculated with $5 \log _{10}$ EID $_{50}$ of LPAIV-1 shed higher virus titers for more days compared to chickens inoculated with LPAIV-2 (Figure 2). All chickens inoculated with $4 \log _{10}$ EID $_{50}$ (Table 1 ) and $6 \log _{10}$ EID $_{50}$ (Table 1 and Figure 2) of the HPAIV shed high virus titers by the OP and CL routes. Only one of five chickens inoculated with $2 \log _{10}$ EID $_{50}$ of the HPAIV shed at $12 \mathrm{hpi}$ and was euthanized due to severe clinical signs (Table 1).

Contact chickens that became infected in the groups inoculated with $6 \log _{10} \operatorname{EID}_{50}$ of the LPAIVs shed low virus titers by both routes (Figure 2). However, chickens exposed by contact to the HPAIV-inoculated chickens did not shed any detectable virus (Figure 2). These contact chickens also did not show clinical signs or seroconverted, so they were not considered infected (Table 1). 
Table 1. Infectivity, lethality, and transmission results from turkeys and chickens inoculated with the US 2020 H7N3 LPAIVs and HPAIV.

\begin{tabular}{|c|c|c|c|c|c|c|c|c|c|c|c|}
\hline \multirow[b]{2}{*}{$\begin{array}{c}\text { Bird } \\
\text { Species }\end{array}$} & \multirow[b]{2}{*}{ Virus } & \multirow[b]{2}{*}{$\begin{array}{l}\text { Dose } \\
\left(\log _{10}\right. \\
\left.\text { EID }_{50}\right)\end{array}$} & \multicolumn{5}{|c|}{ Inoculated } & \multicolumn{4}{|c|}{ Contact Exposed } \\
\hline & & & $\begin{array}{c}\text { No. of Birds } \\
\text { Shedding } \\
\text { Virus } \\
\text { /Total }\end{array}$ & $\begin{array}{l}\text { No. of } \\
\text { Dead } \\
\text { Birds } \\
\text { /Total } \\
\text { (MDT) }^{1}\end{array}$ & $\begin{array}{l}\text { No. of Birds } \\
\text { HI Positive } \\
\text { /Total (Mean } \\
\text { HI Titer) }^{2}\end{array}$ & $\begin{array}{l}\text { No. of } \\
\text { Birds } \\
\text { Infected } \\
\text { /Total }^{3}\end{array}$ & $\begin{array}{c}\text { BID }_{50} \\
\left(\log _{10}\right)^{4}\end{array}$ & $\begin{array}{c}\text { No. of } \\
\text { Birds } \\
\text { Shed- } \\
\text { ding } \\
\text { Virus } \\
\text { /Total }\end{array}$ & $\begin{array}{l}\text { No. of Dead } \\
\text { Birds/Total } \\
\text { (MDT) }\end{array}$ & $\begin{array}{c}\text { No. of } \\
\text { Birds HI } \\
\text { Positive } \\
\text { /Total } \\
\text { (Mean HI }^{\text {Titer) }{ }^{2}}\end{array}$ & $\begin{array}{c}\text { No. of } \\
\text { Birds } \\
\text { Infected } \\
\text { /Total }^{3}\end{array}$ \\
\hline \multirow{9}{*}{ Turkeys } & \multirow{3}{*}{ LPAIV-1 } & 2 & $0 / 4$ & $0 / 4$ & $0 / 4(<3.0)$ & $0 / 4$ & \multirow{3}{*}{2.5} & na & na & na & na \\
\hline & & 3 & $5 / 5$ & $0 / 5$ & $5 / 5(9.4)$ & $5 / 5$ & & $2 / 2$ & $0 / 2$ & $2 / 2(10)$ & $2 / 2$ \\
\hline & & 5 & $5 / 5$ & $0 / 5$ & $5 / 5(9.4)$ & $5 / 5$ & & $2 / 2$ & $0 / 2$ & $2 / 2(10)$ & $2 / 2$ \\
\hline & \multirow{3}{*}{ LPAIV-2 } & 2 & $5 / 5$ & $0 / 5$ & $5 / 5(8.0)$ & $5 / 5$ & \multirow{3}{*}{$<2$} & na & na & na & na \\
\hline & & 3 & $5 / 5$ & $1 / 5^{5}$ & $4 / 4(6.5)$ & $5 / 5$ & & $2 / 2$ & $1 / 2^{5}$ & $1 / 1(8.0)$ & $2 / 2$ \\
\hline & & 5 & $5 / 5$ & $0 / 5$ & $5 / 5(7.6)$ & $5 / 5$ & & $2 / 2$ & $0 / 2$ & $2 / 2(6.0)$ & $2 / 2$ \\
\hline & \multirow{3}{*}{ HPAIV } & 2 & $5 / 5$ & $5 / 5(2.4)$ & na & $5 / 5$ & \multirow{3}{*}{$<2$} & na & na & na & na \\
\hline & & 4 & $5 / 5$ & $5 / 5(2.2)$ & na & $5 / 5$ & & $2 / 2$ & $2 / 2(3)$ & na & $2 / 2$ \\
\hline & & 6 & $5 / 5$ & $5 / 5(2.0)$ & na & $5 / 5$ & & $2 / 2$ & $2 / 2(3)$ & na & $2 / 2$ \\
\hline \multirow{11}{*}{ Chickens } & \multirow{4}{*}{ LPAIV-1 } & 2 & $0 / 5$ & $0 / 5$ & $0 / 5(<3.0)$ & $0 / 5$ & \multirow{4}{*}{5.7} & $0 / 3$ & $0 / 3$ & $0 / 3(<3.0)$ & $0 / 3$ \\
\hline & & 3 & $0 / 5$ & $0 / 5$ & $0 / 5(<3.0)$ & $0 / 5$ & & $0 / 3$ & $0 / 3$ & $0 / 3(<3.0)$ & $0 / 3$ \\
\hline & & 5 & $1 / 8$ & $0 / 8$ & $0 / 5^{6,7}(<3.0)$ & $1 / 8$ & & $0 / 3$ & $0 / 3$ & $0 / 3(<3.0)$ & $0 / 3$ \\
\hline & & 6 & $8 / 8$ & $0 / 8$ & $5 / 5^{6}(6.0)$ & $8 / 8$ & & $3 / 3$ & $0 / 3$ & $1 / 3(5.0)$ & $3 / 3$ \\
\hline & \multirow{4}{*}{ LPAIV-2 } & 2 & $0 / 5$ & $0 / 5$ & $0 / 5(<3.0)$ & $0 / 5$ & \multirow{4}{*}{5.4} & $0 / 3$ & $0 / 3$ & $0 / 3(<3.0)$ & $0 / 3$ \\
\hline & & 3 & $1 / 5$ & $0 / 5$ & $1 / 5(3.0)$ & $1 / 5$ & & $0 / 3$ & $0 / 3$ & $0 / 3(<3.0)$ & $0 / 3$ \\
\hline & & 5 & $1 / 8$ & $0 / 8$ & $0 / 5^{6,7}(3.0)$ & $1 / 8$ & & $0 / 3$ & $0 / 3$ & $0 / 3(<3.0)$ & $0 / 3$ \\
\hline & & 6 & $8 / 8$ & $0 / 8$ & $5 / 5^{6}(4.5)$ & $8 / 8$ & & $3 / 3$ & $0 / 3$ & $1 / 3(7.0)$ & $3 / 3$ \\
\hline & \multirow{3}{*}{ HPAIV } & 2 & $1 / 5$ & $1 / 5(1)$ & $0 / 5(<3.0)$ & $1 / 5$ & \multirow{3}{*}{3.7} & $0 / 3$ & $0 / 3$ & $0 / 3(<3.0)$ & $0 / 3$ \\
\hline & & 4 & $5 / 5$ & $5 / 5(1.6)$ & na & $5 / 5$ & & $0 / 3$ & $0 / 3$ & $0 / 3(<3.0)$ & $0 / 3$ \\
\hline & & 6 & $8 / 8$ & $8 / 8(1.6)$ & na & $8 / 8$ & & $0 / 3$ & $0 / 3$ & $0 / 3(<3.0)$ & $0 / 3$ \\
\hline
\end{tabular}

${ }^{1}$ MDT, mean death time, number of dead birds $\times$ dpi/total dead birds expressed as dpi (days post-inoculation), or dpc, (days postcontact). ${ }^{2}$ Mean HI titers for birds that survived (14 dpi or $13 \mathrm{dpc}$ ). Titer expressed in geometric mean titers (GMT log 2 ). Samples with titers < $3.0 \log _{2}$ GMT were considered negative. ${ }^{3}$ Inoculated or contact birds were considered infected if they shed virus and/or were positive for antibodies at $14 \mathrm{dpi}$ or $13 \mathrm{dpc} .{ }^{4} \mathrm{BID}_{50}: 50 \%$ bird infectious dose. ${ }^{5}$ Birds died of undetermined causes. qRT-PCR positive for at least two time points. ${ }^{6}$ The number of birds is reduced due to necropsy at 2 dpi. ${ }^{7}$ One of the necropsied birds were qRT-PCR positive for at least two time points but serology was unavailable because the bird was euthanized at 2 dpi. na: not applicable.

To compare the amount and duration of virus shedding for all three isolates, areas under the curve (AUC) were calculated using qRT-PCR data from groups inoculated with the highest doses of the isolates ( 5 or $6 \log _{10}$ EID $_{50}$ ) (Figure 3). Except for CL viral shedding by chickens inoculated with $6 \log _{10}$ EID $_{50}$ of LPAIV-2, turkeys have a significantly higher AUC values for virus shedding compared to chickens for LPAIV-1 and LPAIV-2 but not HPAIV (Figure 3). For turkeys, AUCs of OP and CL shedding were significantly different between HPAIV and LPAIV-1 or LPAIV-2. No differences in OP or CL shedding for turkeys were observed between LPAIV-1 and LPAIV-2. For chickens given a $6 \log _{10}$ EID $_{50}$ dose, AUCs for OP shedding were significantly different between HPAIV and LPAIV-1 or LPAIV-2, while AUCs for CL shedding were only statistically significant between HPAIV and LPAIV-1. Statistically significant differences in AUCs between chickens inoculated with $6 \log _{10}$ EID $_{50}$ of LPAIV-1 and LPAIV-2 were only observed for OP shedding but not with CL shedding. Thus, in chickens, AUCs of OP shedding was higher in LPAIV-1 compared to that of LPAIV-2 or HPAIV (Figure 3, Supplementary Table S1).

The brain, heart, lung, muscle, and spleen were collected from necropsied birds for viral quantification by qRT-PCR (Table 2). We analyzed tissues from chickens inoculated with the H7N3 LPAIV-1, LPAIV-2, and the HPAIV. As a result of the reduced number of turkeys, only tissues from HPAIV-inoculated turkeys were collected and examined. In general, results obtained for viral detection in turkey and chicken tissues were consistent with the mortality data, with high virus titers found in most tissues from birds infected with the HPAIV. Turkeys had high titers of virus (ranging from 5.7 to $7.7 \log _{10} \mathrm{EID}_{50}$ ) in all tissues analyzed. Most tissues collected from the HPAIV-infected chickens also had high virus titers, except for one of the chickens from the low-dose group, which had high virus titers $\left(7.4 \log _{10} \mathrm{EID}_{50}\right)$ in the heart and no or low titers in the other tissues, and the chicken from the high-dose group, which had high virus titers in all tissues except the heart (Table 2). Very low or no virus was detected in tissues from the chickens inoculated with the LPAIVs $\left(1.62 \pm 0.1 \log _{10} \operatorname{EID}_{50} ; p<0.05\right)$. 


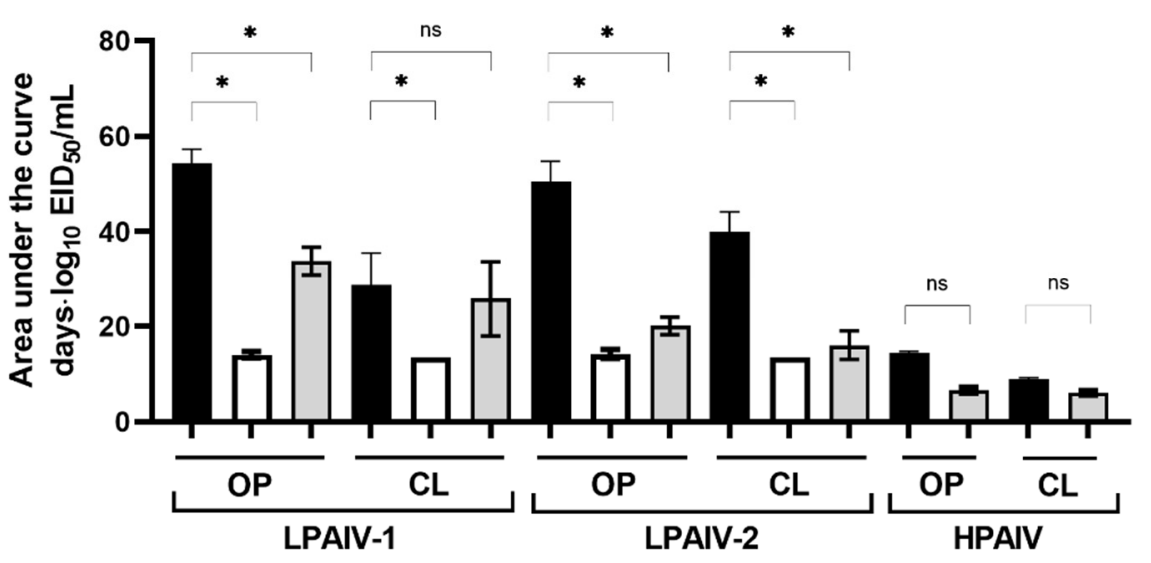

Turkey, LPAIV-1 \& $-2: 10^{5}$ EID $_{50}$ dose HPAIV : $10^{6}$ EID $_{50}$ dose

口 Chicken, $10^{5} \mathrm{EID}_{50}$ dose

$\square$ Chicken, $10^{6} \mathrm{EID}_{50}$ dose

Figure 3. Area under the curve calculation for qRT-PCR data to quantify the amount and duration of virus shed. Asterisks $\left(^{*}\right)$ indicate statistically significant difference between indicated groups (one-way ANOVA with Sidak's multiple comparisons test; $p<0.05)$.

Table 2. Virus detection in tissues of turkeys and chickens inoculated with the 2020 H7N3 HPAIV. Tissues were taken from three birds euthanized at 2 dpi and virus titer was determined by qRT-PCR.

\begin{tabular}{|c|c|c|c|c|c|c|c|}
\hline \multirow{2}{*}{ Species } & \multirow{2}{*}{$\begin{array}{c}\text { Bird } \\
\text { Number }\end{array}$} & \multirow{2}{*}{$\begin{array}{c}\text { Dose Received } \\
\left(\log _{10} \text { EID }_{50}\right)\end{array}$} & \multicolumn{5}{|c|}{ Virus Titer $\left(\log _{10} \mathrm{EID}_{50} / \mathrm{g}\right)$} \\
\hline & & & Brain & Heart & Lung & Muscle & Spleen \\
\hline \multirow{3}{*}{ Turkey } & 1 & 6 & 6.5 & 7.7 & 6.3 & 5.9 & 6.0 \\
\hline & 2 & 6 & 6.7 & 7.0 & 6.2 & 5.8 & 6.0 \\
\hline & 3 & 6 & 6.6 & 7.7 & 6.2 & 5.7 & 6.3 \\
\hline \multirow{3}{*}{ Chicken } & 1 & 2 & 2.5 & 7.4 & - & 2.4 & - \\
\hline & 2 & 4 & 6.8 & 7.5 & 6.4 & 7.0 & 6.8 \\
\hline & 3 & $6 *$ & 7.0 & 1.8 & 6.3 & 7.0 & 6.7 \\
\hline
\end{tabular}

- = negative. * Seven out of the eight chickens that were given a dose of $6 \log _{10} \operatorname{EID}_{50}$ died or were euthanized at 1.5 dpi. Thus, two chickens from other groups (dose 2 and $4 \log _{10}$ EID $_{50}$ ) were chosen for necropsy.

\subsection{Sequence Comparisons of the H7N3 Viruses}

Phylogenetic trees of concatenated genome sequences from the H7N3 outbreak in North and South Carolina were reconstructed as previously reported [13] (Figure 4). All outbreak sequences were highly related to each other with about $99 \%$ pairwise sequence identities in each segment. Thus, the outbreak was likely caused by a single introduction from a wild bird [13]. Moreover, phylogenetic trees of each segment were congruent with the phylogenetic trees constructed from concatenated sequences.

The LPAIV-1 and the HPAIV viruses used in this study belong to the main cluster of outbreak isolates, which is called Cluster A as in [13]. The LPAIV-2 belongs to a distinct cluster of isolates, Cluster $\mathrm{C}$, which branched out early during the outbreak and had a relatively long branch length and is relatively distant to Cluster A [13]. Isolates with the NA stalk deletion, including LPAIV-2, are exclusively found in Cluster C. Pairwise whole genome sequence comparison of the H7N3 inoculum (Table 3) were also consistent with these observations in that LPAIV-1 and HPAIV are more closely related compared to LPAIV-2. Specific nucleotide sequence differences among the isolates were additionally identified and mapped along the genome (Figure 5 and Table 4). Thirty-six amino acid changes were found out of the fifty-seven nucleotide changes enumerated among all pairwise comparisons of isolates characterized in vivo. The major amino acid differences found were the NA stalk deletion in LPAIV-2 and the insertion of the multibasic cleavage site in HPAIV. Other notable changes were R98K, I353V in the nucleoprotein (NP), and G345R in the NA, which have been previously associated with changes in the pathobiology of AIVs in gallinaceous species (Table 4). 

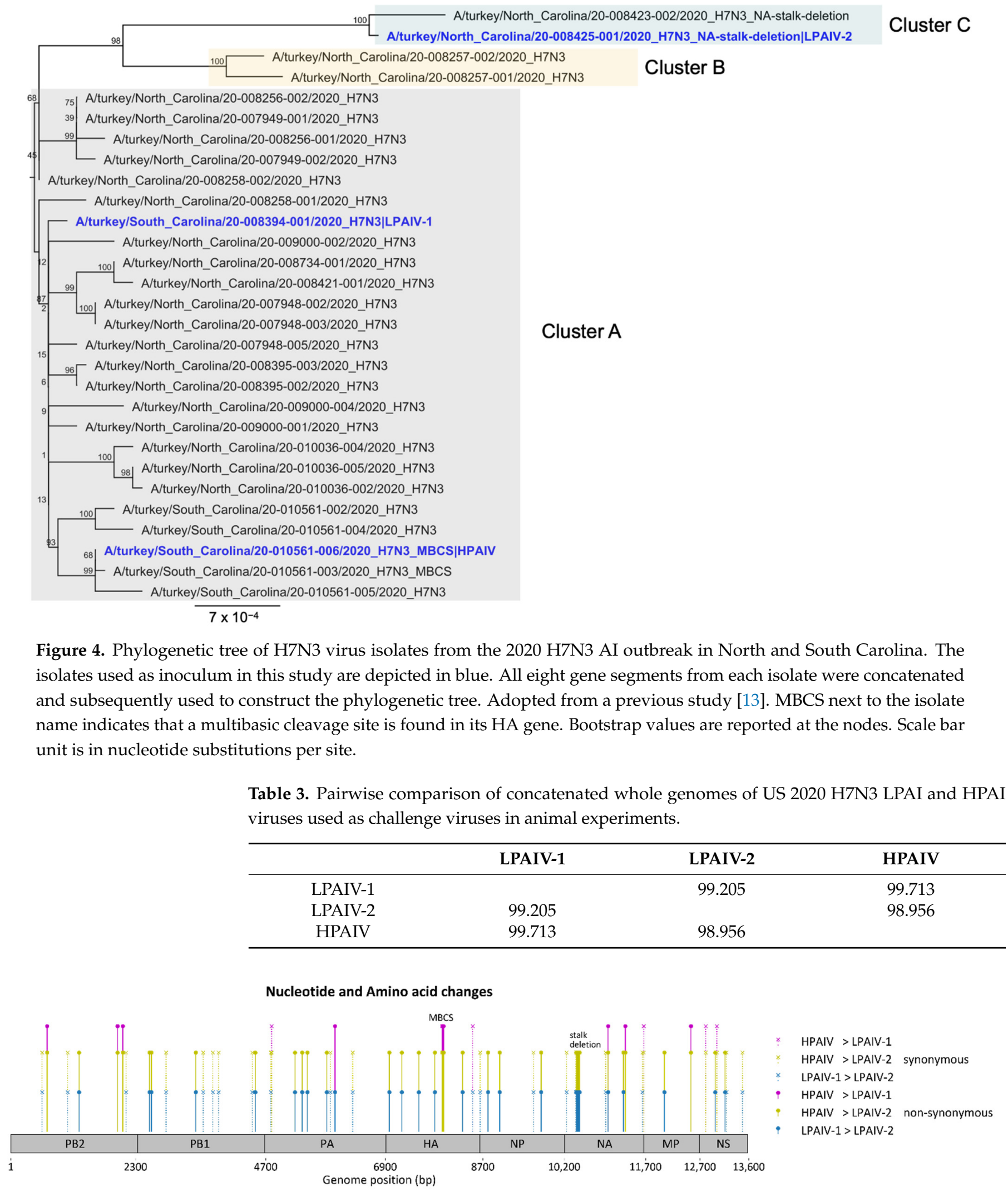

Figure 5. Genomic changes found between the H7N3 viruses used in this study as inoculum. Pairwise comparisons between each pair of viruses were examined. Synonymous and non-synonymous nucleotide changes are mapped onto the concatenated AIV genome. MBCS = multibasic cleavage site. 
Table 4. Important amino acid sequence changes found between the US 2020 H7N3 LPAIVs and HPAIV used as inoculum for the animal experiments. na: not applicable.

\begin{tabular}{|c|c|c|c|c|c|c|c|}
\hline LPAIV-1 & LPAIV-2 & HPAIV & Position & $\begin{array}{c}\text { Amino Acid } \\
\text { Change }\end{array}$ & Protein & References & Remarks \\
\hline na & na & DRKSRHRRI & $339-347$ & $\begin{array}{l}\text { Insertion: } \\
\text { DRKSRHRRI }\end{array}$ & Hemagglutinin & & $\begin{array}{l}\text { Multibasic cleavage } \\
\text { site }\end{array}$ \\
\hline $\mathrm{R}$ & $\mathrm{R}$ & K & 98 & R98K & Nucleoprotein & [33] & $\begin{array}{l}\text { Change found in } \\
\text { samples from } \\
\text { bobwhite quail } \\
\text { infected with a } 2014 \\
\text { H5N2 HPAIV virus } \\
\text { from the US 2014-2015 } \\
\text { H5 outbreak. Also } \\
\text { found in later } 2015 \\
\text { virus isolates from } \\
\text { turkeys in Minnesota. }\end{array}$ \\
\hline na & $\begin{array}{l}\text { LNCSDTIIT } \\
\text { YNNTVIN } \\
\text { NITTTI }\end{array}$ & na & $56-77$ & $\begin{array}{l}\text { Deletion: } \\
\text { LNCSDTI- } \\
\text { ITYNNTVIN- } \\
\text { NITTTI }\end{array}$ & Neuraminidase & $\begin{array}{l}{[16,17,34-} \\
39]\end{array}$ & $\begin{array}{l}\text { Associated with } \\
\text { adaptation to } \\
\text { gallinaceous species }\end{array}$ \\
\hline G & $\mathrm{R}$ & G & 345 & G345R & Neuraminidase & [26] & $\begin{array}{l}\text { Found in a } 2016 \text { H7N3 } \\
\text { virus from Mexico, } \\
\text { when compared to an } \\
\text { earlier } 2012 \text { H7N3 } \\
\text { virus. }\end{array}$ \\
\hline
\end{tabular}

\section{Discussion}

In our laboratory, we routinely conduct standardized studies evaluating the pathobiology of AIVs in different avian species as part of the basic characterization of novel isolates $[9,15,27,40-51]$. These previous studies, as well as this one, provide essential information on the epidemiology of the AIVs and have informed models used to identify what type of samples and when to collect them for optimal virus detection during an outbreak. In this study, we compared the infectivity, transmissibility, and pathogenicity in turkeys and chickens of two LPAIVs, differing by a 66-nucleotide deletion in the NA stalk, and one HPAIV isolate from the H7N3 outbreak in turkeys in North Carolina and South Carolina, US, in 2020. A previous study showed that these H7N3 viruses derived from North American wild bird-origin AIVs and that they are distinct from other recent AIVs causing outbreaks in poultry in the US [13], specifically the H7N8 and H7N9 viruses from outbreaks in Indiana (2016) [11] and Tennessee (2017) [12], respectively, and the H7N3 HPAIV that has been circulating in Mexico since 2012. The 2020 H7N3 HPAIV has a 27-nucleotide insertion that appears derived from turkey host cellular 28S rRNA [13]. Whole genome sequencing determined that the two HPAIV variants isolated from the outbreak were a mix of LPAIV and HPAIV, suggesting that the mutation was caught early and the HPAIV was restricted to a single turkey premise [13]. The limited circulation of the HPAIV is supported by AIV surveillance of the poultry in the area. Interestingly, the insertion at the HA cleavage site is identical to the one found in the 2017 H7N9 HPAIV from the 2017 Tennessee poultry outbreak [12].

Although AIVs have been isolated from hundreds of bird species, the natural reservoirs of the virus are considered to be wild aquatic birds [52,53]. Chickens and turkeys are not natural hosts for AIV, and many wild waterfowl viruses will not easily infect and transmit in chickens and turkeys $[25,54]$. AIVs from wild birds once introduced into gallinaceous species can quickly adapt to the new host $[15,25]$. However, chickens and turkeys are not equally susceptible to the same isolates. The $50 \%$ bird infectious dose $\left(\mathrm{BID}_{50}\right)$, a good measurement of host adaptation, may differ by 100 to 1000-fold between chickens 
and turkeys [25]. Turkeys appear to be more susceptible to AIV infection than chickens for many AIV isolates from wild waterfowl and poultry [15,27,55-57].

HPAIV causes a severe systemic disease with high mortality in chickens, turkeys, and other gallinaceous species [2,3]. LPAIV typically causes mild to moderate respiratory disease and can interrupt egg production in laying hens and turkey breeders [1]. However, in well-managed birds, LPAIV infection can be subclinical, which in commercial poultry may be problematic because the virus can circulate undetected with the risk of mutating and becoming HPAIV. Therefore, it is crucial to continue to conduct surveillance for AIV in poultry. The viruses causing the 2020 H7N3 outbreak were detected quickly, which permitted rapid control and eradication.

All turkeys inoculated with the 2020 H7N3 HPAIV became infected and died within 2 days, resulting in a $\mathrm{BID}_{50}$ of less than $2 \log _{10} \mathrm{EID}_{50}$. In addition, all contact turkeys became infected and died. Although the chickens infected with the HPAIV died within two days, the $\mathrm{BID}_{50}$ was higher $\left(3.7 \log _{10} \mathrm{EID}_{50}\right)$, and the virus did not transmit and infect contact-exposed chickens. These results clearly show the greater susceptibility and transmissibility of 2020 H7N3 HPAIV for turkeys than chickens, as has been previously reported in other HPAIV studies $[14,25,27,58]$. The H7N8 HPAIV from the 2016 outbreak in turkeys [27] also had a BID $_{50}$ below $2 \log _{10} \mathrm{EID}_{50}$ and was transmitted to all contact turkeys, and chickens were also less susceptible with a $\mathrm{BID}_{50}$ of $3.2 \log _{10} \mathrm{EID}_{50}$ and no contact transmission. Interestingly, chickens infected with the 2017 H7N9 HPAIV outbreak were more susceptible to infection [43], the virus having a BID $_{50}$ below $2 \log _{10}$ EID $_{50}$, but the virus still poorly transmitted to contact-exposed chickens [43]. The 2017 H7N9 LPAIV likely persisted longer, based on the wider geographic detections, in the chicken populations having more opportunity to adapt to this host.

Although the hemagglutinin (HA) protein has a significant influence on the pathogenesis of AIVs and is the major determinant of the HPAI phenotype, the neuraminidase (NA) is also involved in virus fitness and immune evasion in the host population [1,2]. The HA and NA are constantly under selective pressure due to the location of these proteins on the envelope of the virus. The two LPAIV isolates used in our study differed in the length of NA stalk region [13], with a 66 nucleotide deletion in the NA of the LPAIV-2 compared to LPAIV-1. A short NA stalk has been previously observed in other AIVs including H2N2, H5N1, H6N1, H7N1, H7N9, H7N3 and H9N2 subtypes [34,35,59-63]. Deletions in the NA stalk have been associated with poultry adaptation [14-17,64], outbreaks in the field [34], and experimental virus passage in gallinaceous birds [37,38]. Other studies showed that influenza viruses with different NA stalk lengths have different in vitro growth characteristics and plaque size $[39,65,66]$ and differences in pathogenesis in ducks and chickens $[39,63]$. A study demonstrated that an amino acid deletion in the NA stalk can remove potential glycosylation sites, which may interfere in the protein's function due to possible changes in the structure and consequently affect the immune response [67].

We analyzed the impact of the NA stalk deletion by comparing two 2020 H7N3 LPAIV isolates with and without such deletion. Our results demonstrate that both H7N3 LPAIV isolates could infect directly inoculated turkeys and transmit to contact-exposed turkeys. However, the virus with the NA deletion (LPAIV-2) was more infectious $\left(\mathrm{BID}_{50}\right.$ of $<2 \log _{10}$ $\left.\mathrm{EID}_{50}\right)$ than the one without (LPAIV-1) $\left(\mathrm{BID}_{50}\right.$ of $\left.2.5 \log _{10} \mathrm{EID}_{50}\right)$, which could indicate that this virus is better adapted to turkeys. The LPAIVs had similar viral shedding patterns to what was observed with the 2016 H7N8 LPAIV in turkeys, with virus shed for many days by both the OP and CL routes [27]. The extensive cloacal virus shedding, which was not observed in the chickens, could in part explain the better transmissibility of these viruses in turkeys, since higher amounts of virus shed into the environment could facilitate transmission. Moreover, the slightly higher infectivity of LPAIV-2 shows that potentially less LPAIV-2 is required to infect a turkey, thereby enabling more efficient transmission given the same amount of virus present in the environment.

Similar data demonstrating the high susceptibility of turkeys to H7 LPAIVs have been previously published $[15,27,43,58]$. In chickens, the LPAIV doses required to infect chickens 
were higher than that was needed for turkeys. For both LPAIVs, all chickens only became infected when given the high virus dose $\left(6 \log _{10} \mathrm{EID}_{50}\right)$, and limited transmission was observed. Although HPAIV is shed by the OP and CL route, the LPAIVs were shed in the highest quantity from the OP route in chickens. Additionally, lower AUCs of LPAIV shedding were generally observed in chickens compared to turkeys. Previous H7 LPAIVs from the US $[27,43]$ when examined in chickens had similar BID $_{50}$ as well as patterns of virus shedding, and they did not transmit to contacts, indicating that these viruses were probably not well adapted to chickens. Interestingly, the presence of the NA stalk deletion did not increase the infectivity of the LPAIV-2 in chickens as seen with the turkeys. Indeed, the LPAIV-1 replicated better than the LPAIV-2, based on virus shedding, indicating that for this virus, the effect of the NA stalk deletion might be species specific. These observations are consistent with the fact that the $2020 \mathrm{H} 7 \mathrm{~N} 3$ outbreak occurred in turkey premises and thus, efficient replication in the turkey host was likely selected for in the H7N3 viruses as the outbreak continued.

Aside from the multibasic cleavage site in the HA and the NA stalk deletion, thirty-six amino acid differences were found among the three 2020 H7N3 viruses, two of which have been previously reported in similar studies. One of them is the R98K change in the nucleoprotein (NP) of the HPAIV. This change was also observed with the Goose/Guangdong lineage H5N2 HPAIVs causing the outbreak in poultry in the US in 2015, suggesting that R98K may be associated with adaptation of HPAIVs in poultry [44]. Another change, the G345R substitution in the NA observed in the LPAIV-2, was also found in H7N3 HPAIV isolates from chickens in Mexico, with the glycine residue observed in the earlier 2012 isolate, whereas the arginine residue was observed in a 2016 isolate [10]. It remains to be determined if the other amino acid changes have a role in adaptation of these viruses in poultry. Since the outbreak was rapidly contained, the viruses had limited opportunity to accumulate changes that could further affect the pathobiology of the viruses.

Analyses from all gene segments of the H7N3 LPAIV and HPAIV isolates from the 2020 outbreak in the US [13] suggest that the precursor for these viruses most likely emerged from wild waterfowl in the Mississippi flyway with occasional spread during migration. Spillover of North American lineage H7 subtype AIV from wild birds into poultry has occurred several times $[6,7,11,12,68]$, highlighting the importance of constant AIV surveillance in wild birds and poultry, and enhanced biosecurity for poultry during periods of wild bird migration.

In conclusion, our results showed that the H7N3 2020 LPAIVs and the HPAIV were more infectious in turkeys than in chickens and were efficiently transmitted to contact turkeys but not chickens, corroborating the high susceptibility of turkeys to AIV infections. This high susceptibility of turkeys to AIV infection, coupled with high titers and duration of virus shed, favored the spread of these AIVs in turkeys. The LPAIV-2 was more infectious to turkeys than LPAIV-1, which was possibly due to the 66 nucleotide deletion at the NA stalk region, but this effect was not seen in chickens. Additional experiments using reverse genetics could help determine possible markers of host adaptation and virulence and better associate the NA stalk length with the differences observed in pathogenesis, infectivity, and transmission between different species. Furthermore, there is a need to understand why changes only occur in specific LPAIV precursors that favor the emergence of HPAIV. Finally, this knowledge will enhance our ability to predict and implement strategies to prevent potential AIV outbreaks.

Supplementary Materials: The following are available online at https:/ /www.mdpi.com/article/ 10.3390/v13091851/s1, Table S1: Statistical comparisons between area under the curves (AUCs) of virus shedding from turkeys and chickens inoculated with H7N3 viruses as measured by qRT-PCR. 
Author Contributions: Conceptualization, M.J.P.-J., M.F.C., C.M.L., E.S., D.E.S. and D.L.S.; methodology, M.J.P.-J., D.E.S., D.L.S., E.S., M.F.C. and C.M.L.; validation, M.J.P.-J., M.F.C. and C.M.L.; formal analysis, M.J.P.-J., M.F.C. and C.M.L.; investigation, M.J.P.-J., M.F.C., C.M.L., T.O., S.Y., S.D., D.J.P. and D.R.K.; resources, M.L.K., M.L.T.; writing—original draft preparation, M.F.C., C.M.L. and M.J.P.-J.; writing-review and editing, M.F.C., C.M.L., M.J.P.-J., T.O., S.Y., S.D., E.S., D.R.K., D.J.P., D.L.S., D.E.S., M.L.K. and M.L.T.; visualization, M.F.C., C.M.L. and M.J.P.-J.; supervision, M.J.P.-J.; project administration, M.J.P.-J.; funding acquisition, D.L.S. and M.J.P.-J. All authors have read and agreed to the published version of the manuscript.

Funding: This research was supported by the United States Department of Agriculture (USDA), Agricultural Research Service (ARS) Project 6612-32000-066-00D, the USDA/ARS- Animal and Plant Health Inspection Service (APHIS) Interagency Agreement \#60-6040-6-005, and the NIH-CEIRS Agreement \#AAI-12004001. This research was also supported in part by an appointment to the ARS Research Participation Program administered by the Oak Ridge Institute for Science and Education (ORISE) through an interagency agreement between the U.S. Department of Energy (DOE) and USDA. ORISE is managed by ORAU under DOE contract number DE-SC0014664. All opinions expressed in this paper are the authors' and do not necessarily reflect the policies and views of USDA, NIH, DOE, or ORAU/ORISE. Mention of trade names or commercial products in this publication is solely for the purpose of providing specific information and does not imply recommendation or endorsement by the USDA. The USDA is an equal opportunity provider and employer.

Institutional Review Board Statement: The study was conducted in accordance with guidelines of the Institutional Animal Care and Use Committee (IACUC) at the US National Poultry Research Center, Athens, Georgia (USNPRC; Animal Use Proposal\# USNPRC-2021-021).

Informed Consent Statement: Not applicable.

Data Availability Statement: The data that support the findings of this study are provided in the figures and tables of the article. Additional information is available from the corresponding author upon reasonable request.

Acknowledgments: We gratefully acknowledge the technical assistance from Scott Lee, Jesse Gallagher, Nikolai Lee, Ricky Zoller, animal care assistance from Charles Foley, Roger Brock, and veterinary care from Anne Hurley-Bacon. We would also like to thank Eric Gonder from Butterball for providing the turkeys.

Conflicts of Interest: The authors declare no conflict of interest.

\section{References}

1. Avian Influenza (Including Infection with High Pathogenicity Avian Influenza Viruses). Manual for Diagnostic Tests and Vaccines for Terrestrial Animals, 2021 edition; World Health Organization (OIE), Posted Online 30 June 2021. Available online: https: //www.oie.int/en/what-we-do/standards/codes-and-manuals/terrestrial-manual-online-access/ (accessed on 6 May 2021).

2. Swayne, D.E.; Suarez, D.L.; Sims, L.D. Influenza. In Diseases of Poultry; John Wiley \& Sons: Hoboken, NJ, USA, 2020; pp. 210-256.

3. Pantin-Jackwood, M.J.; Swayne, D.E. Pathogenesis and pathobiology of avian influenza virus infection in birds. Rev. Sci. Tech. 2009, 28, 113-136. [CrossRef]

4. Lee, D.-H.; Criado, M.F.; Swayne, D.E. Pathobiological Origins and Evolutionary History of Highly Pathogenic Avian Influenza Viruses. Cold Spring Harb. Perspect. Med. 2021, 11, a038679. [CrossRef] [PubMed]

5. Rojas, H.; Moreira, R.; Avalos, P.; Capua, I.; Marangon, S. Avian influenza in poultry in Chile. Vet. Rec. $2002,151,188$.

6. Hirst, M.; Astell, C.R.; Griffith, M.; Coughlin, S.M.; Moksa, M.; Zeng, T.; Smailus, D.E.; Holt, R.; Jones, S.; Marra, M.A.; et al. Novel Avian Influenza H7N3 Strain Outbreak, British Columbia. Emerg. Infect. Dis. 2004, 10, 2192-2195. [CrossRef] [PubMed]

7. Berhane, Y.; Hisanaga, T.; Kehler, H.; Neufeld, J.; Manning, L.; Argue, C.; Handel, K.; Hooper-McGrevy, K.; Jonas, M.; Robinson, J.; et al. Highly Pathogenic Avian Influenza Virus A (H7N3) in Domestic Poultry, Saskatchewan, Canada, 2007. Emerg. Infect. Dis. 2009, 15, 1492-1495. [CrossRef] [PubMed]

8. Maurer-Stroh, S.; Lee, R.T.C.; Gunalan, V.; Eisenhaber, F. The highly pathogenic H7N3 avian influenza strain from July 2012 in Mexico acquired an extended cleavage site through recombination with host $28 \mathrm{~S}$ rRNA. Virol. J. 2013, 10, 139. [CrossRef] [PubMed]

9. Kapczynski, D.R.; Pantin-Jackwood, M.; Guzman, S.G.; Ricardez, Y.; Spackman, E.; Bertran, K.; Suarez, D.L.; Swayne, D. Characterization of the 2012 Highly Pathogenic Avian Influenza H7N3 Virus Isolated from Poultry in an Outbreak in Mexico: Pathobiology and Vaccine Protection. J. Virol. 2013, 87, 9086-9096. [CrossRef] 
10. Youk, S.; Lee, D.-H.; Ferreira, H.L.; Afonso, C.L.; Absalon, A.E.; Swayne, D.E.; Suarez, D.L.; Pantin-Jackwood, M.J. Rapid evolution of Mexican H7N3 highly pathogenic avian influenza viruses in poultry. PLoS ONE 2019, 14, e0222457. [CrossRef] [PubMed]

11. Killian, M.L.; Kim-Torchetti, M.; Hines, N.; Yingst, S.; DeLiberto, T.; Lee, D.-H. Outbreak of H7N8 Low Pathogenic Avian Influenza in Commercial Turkeys with Spontaneous Mutation to Highly Pathogenic Avian Influenza. Genome Announc. 2016, 4, e00457-16. [CrossRef]

12. Lee, D.H.; Torchetti, M.K.; Killian, M.L.; Berhane, Y.; Swayne, D.E. Highly Pathogenic Avian Influenza A(H7N9) Virus, Tennessee, USA, March 2017. Emerg. Infect. Dis. 2017, 23, 1860-1863. [CrossRef]

13. Youk, S.; Lee, D.-H.; Killian, M.L.; Pantin-Jackwood, M.J.; Swayne, D.E.; Torchetti, M.K. Highly Pathogenic Avian Influenza A(H7N3) Virus in Poultry, United States, 2020. Emerg. Infect. Dis. 2020, 26, 2966-2969. [CrossRef]

14. Li, J.; Zu Dohna, H.; Cardona, C.J.; Miller, J.; Carpenter, T.E. Emergence and Genetic Variation of Neuraminidase Stalk Deletions in Avian Influenza Viruses. PLoS ONE 2011, 6, e14722. [CrossRef] [PubMed]

15. Spackman, E.; Gelb, J.; Preskenis, L.A.; Ladman, B.S.; Pope, C.R.; Pantin-Jackwood, M.J.; McKinley, E.T. The pathogenesis of low pathogenicity $\mathrm{H} 7$ avian influenza viruses in chickens, ducks and turkeys. Virol. J. 2010, 7, 331. [CrossRef] [PubMed]

16. Hoffmann, T.W.; Munier, S.; Larcher, T.; Soubieux, D.; Ledevin, M.; Esnault, E.; Tourdes, A.; Croville, G.; Guerin, J.-L.; Quere, P.; et al. Length Variations in the NA Stalk of an H7N1 Influenza Virus Have Opposite Effects on Viral Excretion in Chickens and Ducks. J. Virol. 2011, 86, 584-588. [CrossRef]

17. Munier, S.; Larcher, T.; Cormier-Aline, F.; Soubieux, D.; Su, B.; Guigand, L.; Labrosse, B.; Cherel, Y.; Quéré, P.; Marc, D.; et al. A Genetically Engineered Waterfowl Influenza Virus with a Deletion in the Stalk of the Neuraminidase Has Increased Virulence for Chickens. J. Virol. 2010, 84, 940-952. [CrossRef]

18. Swayne, D.; Senne, D.; Beard, C. Influenza; American Association of Avian Pathologists: Kennett Square, PA, USA, 1998.

19. Chrzastek, K.; Lee, D.-H.; Smith, D.; Sharma, P.; Suarez, D.; Pantin-Jackwood, M.J.; Kapczynski, D.R. Use of Sequence-Independent, Single-Primer-Amplification (SISPA) for rapid detection, identification, and characterization of avian RNA viruses. Virology 2017, 509, 159-166. [CrossRef] [PubMed]

20. Horimoto, T.; Kawaoka, Y. Molecular Changes in virulent mutants arising from avirulent avian influenza viruses during Replication in 14-day-old embryonated eggs. Virology 1995, 206, 755-759. [CrossRef]

21. Lee, C.W.; Lee, Y.J.; Swayne, D.; Senne, D.; Linares, D.J.; Suarez, D. Assessing potential pathogenicity of avian influenza virus: Current and experimental system. Avian Dis. 2007, 51, 260-263. [CrossRef]

22. Li, H. Aligning Sequence Reads, Clone Sequences and Assembly Contigs with BWA-MEM. arXiv 2013, arXiv:1303.3997. Available online: https:/ / www.arxiv-vanity.com/papers/1303.3997/ (accessed on 24 June 2018).

23. Dimitrov, K.M.; Sharma, P.; Volkening, J.D.; Goraichuk, I.V.; Wajid, A.; Rehmani, S.F.; Basharat, A.; Shittu, I.; Joannis, T.M.; Miller, P.J.; et al. A robust and cost-effective approach to sequence and analyze complete genomes of small RNA viruses. Virol. J. 2017, 14, 72. [CrossRef]

24. Wilm, A.; Aw, P.P.K.; Bertrand, D.; Yeo, G.H.T.; Ong, S.H.; Wong, C.H.; Khor, C.C.; Petric, R.; Hibberd, M.L.; Nagarajan, N. LoFreq: A sequence-quality aware, ultra-sensitive variant caller for uncovering cell-population heterogeneity from high-throughput sequencing datasets. Nucleic Acids Res. 2012, 40, 11189-11201. [CrossRef]

25. Swayne, D.E.; Slemons, R.D. Using Mean Infectious Dose of High- and Low-Pathogenicity Avian Influenza Viruses Originating from Wild Duck and Poultry as One Measure of Infectivity and Adaptation to Poultry. Avian Dis. 2008, 52, 455-460. [CrossRef]

26. Youk, S.-S.; Lee, D.-H.; Leyson, C.M.; Smith, D.; Criado, M.F.; DeJesus, E.; Swayne, D.; Pantin-Jackwood, M.J. Loss of Fitness of Mexican H7N3 Highly Pathogenic Avian Influenza Virus in Mallards after Circulating in Chickens. J. Virol. 2019, 93, e00543-19. [CrossRef]

27. Spackman, E.; Prosser, D.J.; Pantin-Jackwood, M.J.; Berlin, A.M.; Stephens, C.B. The Pathogenesis of Clade 2.3.4.4 H5 Highly Pathogenic Avian Influenza Viruses in Ruddy Duck (Oxyura Jamaicensis) and Lesser Scaup (Aythya affinis). J. Wildl. Dis. 2017, 53, 832-842. [CrossRef] [PubMed]

28. Pedersen, J.C. Hemagglutination-Inhibition Assay for Influenza VIrus Subtype Identification and the Detection and Quantification of Serum Antibodies to Influenza Virus. In Animal Influenza Virus; Spackman, E., Ed.; Humana Press: Totova, NJ, USA, 2014.

29. Reed, L.J.; Muench, H. A simple method of estimating fifty percent endpoints. Am. J. Epidemiol. 1938, 27, 493-497. [CrossRef]

30. Lee, C.-W.; Suarez, D.L. Application of real-time RT-PCR for the quantitation and competitive replication study of H5 and H7 subtype avian influenza virus. J. Virol. Methods 2004, 119, 151-158. [CrossRef] [PubMed]

31. Katoh, K.; Misawa, K.; Kuma, K.I.; Miyata, T. MAFFT: A novel method for rapid multiple sequence alignment based on fast Fourier transform. Nucleic Acids Res. 2002, 30, 3059-3066. [CrossRef] [PubMed]

32. Miller, M.A.; Pfeiffer, W.; Schwartz, T. Creating the CIPRES Science Gateway for inference of large phylogenetic trees. In Proceedings of the 2010 Gateway Computing Environments Workshop (GCE), New Orleans, LA, USA, 14 November 2010; pp. 1-8. [CrossRef]

33. Bertran, K.; Lee, D.-H.; Pantin-Jackwood, M.J.; Spackman, E.; Balzli, C.; Suarez, D.L.; Swayne, D.E. Pathobiology of Clade 2.3.4.4 H5Nx High-Pathogenicity Avian Influenza Virus Infections in Minor Gallinaceous Poultry Supports Early Backyard Flock Introductions in the Western United States in 2014-2015. J. Virol. 2017, 91, e00960-17. [CrossRef] 
34. Banks, J.; Speidel, E.S.; Moore, E.; Plowright, L.; Piccirillo, A.; Capua, I.; Cordioli, P.; Fioretti, A.; Alexander, D.J. Changes in the haemagglutinin and the neuraminidase genes prior to the emergence of highly pathogenic H7N1 avian influenza viruses in Italy. Arch. Virol. 2001, 146, 963-973. [CrossRef]

35. Campitelli, L.; Mogavero, E.; De Marco, M.A.; Delogu, M.; Puzelli, S.; Frezza, F.; Facchini, M.; Chiapponi, C.; Foni, E.; Cordioli, P.; et al. Interspecies transmission of an H7N3 influenza virus from wild birds to intensively reared domestic poultry in Italy. Virology 2004, 323, 24-36. [CrossRef]

36. Durrant, J.D.; Bush, R.M.; Amaro, R.E. Microsecond Molecular Dynamics Simulations of Influenza Neuraminidase Suggest a Mechanism for the Increased Virulence of Stalk-Deletion Mutants. J. Phys. Chem. B 2016, 120, 8590-8599. [CrossRef]

37. Giannecchini, S.; Clausi, V.; Di Trani, L.; Falcone, E.; Terregino, C.; Toffan, A.; Cilloni, F.; Matrosovich, M.; Gambaryan, A.S.; Bovin, N.V.; et al. Molecular adaptation of an H7N3 wild duck influenza virus following experimental multiple passages in quail and turkey. Virology 2010, 408, 167-173. [CrossRef] [PubMed]

38. Dlugolenski, D.; Jones, L.; Saavedra, G.; Tompkins, S.M.; Tripp, R.A.; Mundt, E. Passage of low-pathogenic avian influenza (LPAI) viruses mediates rapid genetic adaptation of a wild-bird isolate in poultry. Arch. Virol. 2011, 156, 565-576. [CrossRef] [PubMed]

39. Chen, S.; Quan, K.; Wang, D.; Du, Y.; Qin, T.; Peng, D.; Liu, X. Truncation or Deglycosylation of the Neuraminidase Stalk Enhances the Pathogenicity of the H5N1 Subtype Avian Influenza Virus in Mallard Ducks. Front. Microbiol. 2020, 11, 583588. [CrossRef] [PubMed]

40. Pantin-Jackwood, M.J.; Miller, P.J.; Spackman, E.; Swayne, D.E.; Susta, L.; Costa-Hurtado, M.; Suarez, D.L. Role of Poultry in the Spread of Novel H7N9 Influenza Virus in China. J. Virol. 2014, 88, 5381-5390. [CrossRef]

41. Spackman, E.; Pantin-Jackwood, M.; Swayne, D.E.; Suarez, D.L.; Kapczynski, D.R. Impact of route of exposure and challenge dose on the pathogenesis of H7N9 low pathogenicity avian influenza virus in chickens. Virology 2015, 477, 72-81. [CrossRef] [PubMed]

42. Perkins, L.E.L.; Swayne, D. Comparative Susceptibility of Selected Avian and Mammalian Species to a Hong Kong-Origin H5N1 High-Pathogenicity Avian Influenza Virus. Avian Dis. 2003, 47, 956-967. [CrossRef]

43. Bertran, K.; Lee, D.-H.; Criado, M.F.; Smith, D.; Swayne, D.E.; Pantin-Jackwood, M.J. Pathobiology of Tennessee 2017 H7N9 low and high pathogenicity avian influenza viruses in commercial broiler breeders and specific pathogen free layer chickens. Vet. Res. 2018, 49, 82. [CrossRef] [PubMed]

44. Pantin-Jackwood, M.J.; Costa-Hurtado, M.; Bertran, K.; DeJesus, E.; Smith, D.; Swayne, D.E. Infectivity, transmission and pathogenicity of H5 highly pathogenic avian influenza clade 2.3.4.4 (H5N8 and H5N2) United States index viruses in Pekin ducks and Chinese geese. Vet. Res. 2017, 48, 33. [CrossRef]

45. Bertran, K.; Pantin-Jackwood, M.J.; Criado, M.F.; Lee, D.-H.; Balzli, C.L.; Spackman, E.; Suarez, D.L.; Swayne, D.E. Pathobiology and innate immune responses of gallinaceous poultry to clade 2.3.4.4A H5Nx highly pathogenic avian influenza virus infection. Vet. Res. 2019, 50, 89. [CrossRef]

46. Bertran, K.; Swayne, D.E.; Pantin-Jackwood, M.J.; Kapczynski, D.R.; Spackman, E.; Suarez, D.L. Lack of chicken adaptation of newly emergent Eurasian H5N8 and reassortant H5N2 high pathogenicity avian influenza viruses in the U.S. is consistent with restricted poultry outbreaks in the Pacific flyway during 2014-2015. Virology 2016, 494, 190-197. [CrossRef] [PubMed]

47. Leyson, C.; Youk, S.; Smith, D.; Dimitrov, K.; Lee, D.-H.; Larsen, L.E.; Swayne, D.E.; Pantin-Jackwood, M.J. Pathogenicity and genomic changes of a 2016 European H5N8 highly pathogenic avian influenza virus (clade 2.3.4.4) in experimentally infected mallards and chickens. Virology 2019, 537, 172-185. [CrossRef]

48. Pantin-Jackwood, M.J.; Costa-Hurtado, M.; Shepherd, E.; DeJesus, E.; Smith, D.; Spackman, E.; Kapczynski, D.R.; Suarez, D.L.; Stallknecht, D.E.; Swayne, D. Pathogenicity and Transmission of H5 and H7 Highly Pathogenic Avian Influenza Viruses in Mallards. J. Virol. 2016, 90, 9967-9982. [CrossRef]

49. Spackman, E.; Prosser, D.J.; Pantin-Jackwood, M.; Stephens, C.B.; Berlin, A.M. Clade 2.3.4.4 H5 North American Highly Pathogenic Avian Influenza Viruses Infect, but Do Not Cause Clinical Signs in, American Black Ducks (Anas rubripes). Avian Dis. 2019, 63, 366-370. [CrossRef]

50. Stephens, C.B.; Prosser, D.J.; Pantin-Jackwood, M.J.; Berlin, A.M.; Spackman, E. The Pathogenesis of H7 Highly Pathogenic Avian Influenza Viruses in Lesser Scaup (Aythya affinis). Avian Dis. 2019, 63, 230-234. [CrossRef]

51. Luczo, J.M.; Prosser, D.J.; Pantin-Jackwood, M.J.; Berlin, A.M.; Spackman, E. The pathogenesis of a North American H5N2 clade 2.3.4.4 group A highly pathogenic avian influenza virus in surf scoters (Melanitta perspicillata). BMC Vet. Res. 2020, 16, 351. [CrossRef]

52. Slemons, R.D.; Johnson, D.C.; Osborn, J.S.; Hayes, F. Type-A Influenza Viruses Isolated from Wild Free-Flying Ducks in California. Avian Dis. 1974, 18, 119-124. [CrossRef]

53. Stallknecht, D.E.; Brown, J.D. Ecology of Avian Influenza in Wild Birds. In Avian Influenza; Wiley: Hoboken, NJ, USA, 2009; pp. 43-58.

54. Halvorson, D.A.; Kelleher, C.J.; Senne, D.A. Epizootiology of avian influenza: Effect of season on incidence in sentinel ducks and domestic turkeys in Minnesota. Appl. Environ. Microbiol. 1985, 49, 914-919. [CrossRef]

55. Morales, A.C., Jr.; Hilt, D.A.; Williams, S.M.; Pantin-Jackwood, M.J.; Suarez, D.L.; Spackman, E.; Stallknecht, D.E.; Jackwood, M.W. Biologic characterization of H4, H6, and $\mathrm{H} 9$ type low pathogenicity avian influenza viruses from wild birds in chickens and turkeys. Avian Dis. 2009, 53, 552-562. [CrossRef] [PubMed]

56. Pillai, S.P.S.; Pantin-Jackwood, M.; Suarez, D.; Saif, Y.M.; Lee, C.-W. Pathobiological characterization of low-pathogenicity H5 avian influenza viruses of diverse origins in chickens, ducks and turkeys. Arch. Virol. 2010, 155, 1439-1451. [CrossRef] [PubMed] 
57. Pillai, S.P.; Pantin-Jackwood, M.; Yassine, H.M.; Saif, Y.M.; Lee, C.W. The high susceptibility of turkeys to influenza viruses of different origins implies their importance as potential intermediate hosts. Avian Dis. 2010, 54, 522-526. [CrossRef]

58. Tumpey, T.M.; Kapczynski, D.R.; Swayne, D. Comparative Susceptibility of Chickens and Turkeys to Avian Influenza A H7N2 Virus Infection and Protective Efficacy of a Commercial Avian Influenza H7N2 Virus Vaccine. Avian Dis. 2004, 48, 167-176. [CrossRef] [PubMed]

59. Matrosovich, M.; Zhou, N.; Kawaoka, Y.; Webster, R. The surface glycoproteins of H5 influenza viruses isolated from humans, chickens, and wild aquatic birds have distinguishable properties. J. Virol. 1999, 73, 1146-1155. [CrossRef] [PubMed]

60. Matsuoka, Y.; Swayne, D.; Thomas, C.; Rameix-Welti, M.-A.; Naffakh, N.; Warnes, C.; Altholtz, M.; Donis, R.; Subbarao, K. Neuraminidase Stalk Length and Additional Glycosylation of the Hemagglutinin Influence the Virulence of Influenza H5N1 Viruses for Mice. J. Virol. 2009, 83, 4704-4708. [CrossRef]

61. Sorrell, E.M.; Song, H.; Pena, L.; Perez, D.R. A 27-Amino-Acid Deletion in the Neuraminidase Stalk Supports Replication of an Avian H2N2 Influenza A Virus in the Respiratory Tract of Chickens. J. Virol. 2010, 84, 11831-11840. [CrossRef]

62. Gao, R.; Cao, B.; Hu, Y.; Feng, Z.; Wang, D.; Hu, W.; Chen, J.; Jie, Z.; Qiu, H.; Xu, K.; et al. Human Infection with a Novel Avian-Origin Influenza A (H7N9) Virus. N. Engl. J. Med. 2013, 368, 1888-1897. [CrossRef]

63. Sun, Y.; Tan, Y.; Wei, K.; Sun, H.; Shi, Y.; Pu, J.; Yang, H.; Gao, G.F.; Yin, Y.; Feng, W.; et al. Amino Acid 316 of Hemagglutinin and the Neuraminidase Stalk Length Influence Virulence of H9N2 Influenza Virus in Chickens and Mice. J. Virol. 2012, 87, 2963-2968. [CrossRef] [PubMed]

64. Mo, J.; Youk, S.; Pantin-Jackwood, M.J.; Suarez, D.L.; Lee, D.-H.; Killian, M.L.; Bergeson, N.H.; Spackman, E. The pathogenicity and transmission of live bird market H2N2 avian influenza viruses in chickens, Pekin ducks, and guinea fowl. Vet. Microbiol. 2021, 260, 109180. [CrossRef] [PubMed]

65. Wang, Q.-Z.; Long, J.-X.; Hu, S.-L.; Wu, Y.-T.; Liu, X.-F. Biological significance of amino acids deletion in NA stalk of H5N1 avian influenza virus. Acta Microbiol. Sin. 2006, 46, 542-546.

66. Luo, G.; Chung, J.; Palese, P. Alterations of the stalk of the influenza virus neuraminidase: Deletions and insertions. Virus Res. 1993, 29, 141-153. [PubMed]

67. Kim, P.; Jang, Y.H.; Bin Kwon, S.; Lee, C.M.; Han, G.; Seong, B.L. Glycosylation of Hemagglutinin and Neuraminidase of Influenza A Virus as Signature for Ecological Spillover and Adaptation among Influenza Reservoirs. Viruses 2018, 10, 183. [CrossRef] [PubMed]

68. World Organisation for Animal Health Avian Influenza Portal. Available online: http://www.oie.int/en/animal-health-in-theworld/update-on-avian-influenza/ (accessed on 5 January 2021). 